\title{
Nelfinavir Inhibits the Growth of Small-cell Lung Cancer Cells and Patient-derived Xenograft Tumors
}

\author{
SHIGERU KAWABATA*, NICK CONNIS, JOELL J. GILLS, CHRISTINE L. HANN and PHILLIP A. DENNIS** \\ Department of Oncology, Johns Hopkins University School of Medicine, Baltimore, MD, U.S.A.
}

\begin{abstract}
Background/Aim: Small-cell lung cancer (SCLC) is aggressive and confers poor prognosis. Although SCLC shows more response to chemotherapy than other types of lung cancer, it is difficult to cure because of its frequent recurrence. New drugs and molecular targets need to be identified. Materials and Methods: We investigated the effect of nelfinavir, an HIV protease inhibitor, on SCLC cells and in preclinical treatment studies using SCLC patient-derived xenograft (PDX) mouse models. Results: Nelfinavir inhibited SCLC cell proliferation and induced cell death in vitro, which was caused by induction of the unfolded protein response (UPR), inhibition of mammalian/mechanistic target of rapamycin (mTOR) activation, and reduction in the expression of SCLC-related molecules such as achaete-scute homolog 1 (ASCL1). In vivo, nelfinavir inhibited the growth of SCLC PDX tumors, which correlated with the induction of UPR and reduced expression of ASCL1. Conclusion: Nelfinavir is highly effective in SCLC in vitro and in vivo, suggesting possible incorporation of nelfinavir into clinical trials for patients with SCLC.
\end{abstract}

Small-cell lung cancer (SCLC) comprises $10-15 \%$ of all lung cancer cases. Because of its rarity, it is difficult to evaluate the molecular and functional characteristics of SCLC, resulting in the underdevelopment of new therapies compared with nonsmall cell lung cancer (NSCLC). Although SCLC shows more

This article is freely accessible online.

Current address: *Department of Pathology, Osaka Medical College Faculty of Medicine, Takatsuki City, Osaka, Japan; **Global Clinical Lead, Lung Cancer Immuno-Oncology, AstraZeneca, Gaithersburg, MD, U.S.A.

Correspondence to: Shigeru Kawabata, Department of Pathology, Osaka Medical College Faculty of Medicine, 2-7 Daigakumachi, Bldg. C01, Fifth Floor, Takatsuki City, Osaka 569-8686 Japan. Tel: +81 726831221 (Ext. 8529), Fax: +81 726846513, e-mail: pa1030@osaka-med.ac.jp

Key Words: Small-cell lung cancer, nelfinavir, patient-derived xenograft tumors. response to chemotherapy than other types of lung cancer, it is difficult to cure because of its frequent recurrence (1). Recent evidence shows that critical oncogenic changes such as inactivation of tumor protein p53 (TP53) and retinoblastoma 1 $(R B 1)$ genes, are found in nearly all human SCLC tumors, and amplifications of the myelocytomatosis oncogene (MYC) family or fibroblast growth factor receptor (FGFRl) tyrosine kinase gene (2). Additionally, ASCL1 is a transcription factor that is required for the development of pulmonary neuroendocrine cells and is reported as a lineage-dependent oncogene that plays a role in tumorigenesis arising from dysregulation of genes involved in normal development $(3,4)$. SRY-box transcription factor 2 (SOX2) is a transcription factor that maintains selfrenewal and pluripotency of undifferentiated embryonic stem cells, and has been identified as a gene amplified in SCLC (5). Therapeutic developments targeting these genetic alterations in SCLC are thus necessary.

Previously, we demonstrated that nelfinavir, a human immunodeficiency virus protease inhibitor, inhibited the proliferation of NSCLC cells in vitro and in human NSCLC xenograft tumors by inducing endoplasmic reticulum stress and apoptosis (6). Additionally, nelfinavir shows synergistic effects on NSCLC and multiple myeloma cells with a proteasome inhibitor, bortezomib, by enhancing endoplasmic reticulum stress (7). Nelfinavir has been repurposed as an anticancer drug for lung cancer. More recently, we reported the data of a phase I trial of nelfinavir in adults with solid tumors. Nelfinavir is well-tolerated and shows antitumor activity, particularly in patients with neuroendocrine carcinoma of the midgut and pancreas (8). These findings led us to hypothesize that nelfinavir shows efficacy against SCLC, especially the neuroendocrine carcinoma subtype. We assessed the efficacy of nelfinavir against SCLC cells and conducted an analysis of signal transduction to investigate new molecular therapeutic targets in vitro and in preclinical treatment studies using SCLC patient-derived xenograft (PDX) mouse models.

\section{Materials and Methods}

Reagents. Nelfinavir used in the in vitro studies was obtained through the National Institutes of Health AIDS Research and Reference 
Reagent Program, Division of AIDS, NIAID, National Institutes of Health. Nelfinavir used in the in vivo study was obtained from Pfizer Inc. (New York, NY, USA). Rapamycin (an inhibitor of mechanistic target of rapamycin kinase, mTOR) and tunicamycin (endoplasmic reticulum stress inducer) were obtained from LC Laboratories (Woburn, MA, USA) and Sigma (St. Louis, MO, USA), respectively. Primary antibodies for aurora B, actin, c-MYC (D84C12), SOX2 (D6D9), activating transcription factor 4 (ATF4, D4B8), CCAATenhancer-binding protein homologous protein (CHOP, L63F7), sestrin-2 (SESN2, D1B6), phospho-5' AMP-activated protein kinase $\alpha$ (P-AMPK $\alpha$, Thr 172) (40H9), AMPK $\alpha$, P-S6 ribosomal protein (Ser235/236), S6 ribosomal protein, cleaved/total poly ADP-ribose polymerase (PARP), protein kinase B (AKT), P-AKT (Ser473, D9E), and glyceraldehyde-3-phosphate dehydrogenase (GAPDH) were from Cell Signaling Technology (Beverly, MA, USA). Anti-n-MYC (C-19), 1-MYC (C-20), and ATF3 (C-19) antibodies were from Santa Cruz Biotechnology (Santa Cruz, CA, USA). Anti-ASCL1 (MASH1, clone 24B72D11.1) and a-tubulin antibodies were purchased from BD Pharmingen $^{\mathrm{TM}}$ (San Jose, CA, USA) and Sigma, respectively.

Cell cultures. SCLC (H526, H82, H146, and H69) cell lines were kindly provided by Dr. Charles M. Rudin (Memorial Sloan Kettering Cancer Center, New York, NY, USA). H146 and H69 cells express SOX2 (5). All cell lines were maintained in $75 \mathrm{~cm}^{2}$ flasks in RPMI 1640 (Life Technologies, Grand Island, NY, USA) with $5 \%$ fetal bovine serum (Life Technologies) at $37^{\circ} \mathrm{C}$ in an incubator with $5.0 \% \mathrm{CO}_{2}$.

Cell proliferation assay. SCLC cells (15,000 live cells per well) were plated in 96-well plates and treated with the following drugs dissolved in dimethyl sulfoxide (DMSO) for $72 \mathrm{~h}$ at increasing concentrations of between 1.25 and $20 \mu \mathrm{M}$ for nelfinavir, 0.1 and $1000 \mathrm{nM}$ for rapamycin, or 0.01 and $10 \mu \mathrm{g} / \mathrm{ml}$ for tunicamycin. Growth inhibition was determined using the WST1 assay according to the manufacturer's protocol (Roche Diagnostics; Indianapolis, IN, USA). The percentage growth value was calculated using the absorbance values of untreated cells on day $0\left(\mathrm{D}_{0}\right)$, and of DMSOtreated control cells $(\mathrm{C})$, and drug-treated cells $(\mathrm{T})$ as follows: [(T $\left.\left.-\mathrm{D}_{0}\right) /\left(\mathrm{C}-\mathrm{D}_{0}\right)\right] \times 100$ for concentrations for which $\mathrm{T} \geq \mathrm{D}_{0}$, or $[(\mathrm{T}-$ $\left.\left.\mathrm{D}_{0}\right) / \mathrm{D}_{0}\right] \times 100$ for concentrations for which $\mathrm{T}<\mathrm{D}_{0}$. Experiments were performed three times, and each drug concentration was evaluated in sextuplet wells for a given experiment.

Cell death assay. Cells $\left(2.5 \times 10^{5}\right.$ cells per well) were plated in 12 well plates and treated with nelfinavir at $10 \mu \mathrm{M}$ or an equal volume of DMSO for $72 \mathrm{~h}$. Following incubation, cells were harvested and resuspended in a solution of $1 \mathrm{mg} / \mathrm{ml}$ propidium iodide in phosphate-buffered saline and then immediately acquired on the FL3 channel of a flow cytometer using a Becton Dickinson FACSort and by manual gating using CellQuest software (FACSort, BD Biosciences, San Jose, CA, USA). The propidium iodide-positive population of cells was considered non-viable, whereas the propidium iodide-negative population was considered viable.

Immunoblotting analysis. Cells $\left(5 \times 10^{5}\right.$ cells per well $)$ were plated in 6-well plates and treated with nelfinavir at $10 \mu \mathrm{M}$ or $20 \mu \mathrm{M}$ for 4,12 , or $24 \mathrm{~h}$; rapamycin at $100 \mathrm{nM}$ for $12 \mathrm{~h}$; tunicamycin at $1 \mu \mathrm{g} / \mathrm{ml}$ for 12 $\mathrm{h}$; or an equal volume of DMSO and then lysed in $2 \times$ lysis buffers as described previously (22). For tumor-tissue homogenates in vivo, frozen tumors were allowed to thaw on ice, then homogenized in radioimmunoprecipitation assay buffer $[150 \mathrm{mmol} / \mathrm{l} \mathrm{NaCl}, 1 \%$ Igepal CA-630, $0.5 \%$ sodium deoxycholate, $0.1 \%$ sodium dodecyl sulphate, $50 \mathrm{mmol} / \mathrm{l}$ Tris $(\mathrm{pH} 8.0)]$ containing $2.5 \mathrm{~mol} / \mathrm{l} \mathrm{h}$-glycerol phosphate, $0.2 \mathrm{~mol} / \mathrm{l}$ sodium orthovanadate, $1.25 \mathrm{~mol} / \mathrm{l}$ sodium fluoride, and $1 \times$ protease inhibitor cocktail (Roche Diagnostics) using a hand-held Tissue-Tearor homogenizer (Biospec Products, Bartlesville, OK, USA). Cell lysates or tumor-tissue homogenates with equal amounts of protein were separated using sodium dodecyl sulphatepolyacrylamide gel electrophoresis and then transferred to nitrocellulose membranes. The membranes were blocked for $1 \mathrm{~h}$ in blocking buffer ( $1 \times$ TBS, $5 \%$ milk, $0.1 \%$ Tween 20$)$ and placed in primary antibodies described above, which were diluted in $1 \times$ TBS, $5 \%$ bovine serum albumin, $0.1 \%$ Tween 20 , overnight at $4^{\circ} \mathrm{C}$. On the following day, membranes were washed three times in wash buffer $(0.1 \%$ Tween $20,1 \times$ TBS $)$. Primary antibodies were detected using horseradish peroxidase-linked secondary antibodies and visualized with the enhanced chemiluminescent detection system (Amersham Biosciences, Pittsburgh, PA, USA). Immunoblot experiments were performed at least three times.

Drug treatment SCLC PDX models. LX48 and LX44 PDX tumor cells were isolated from patients with extended-stage SCLC and were maintained solely in immunocompromised mice by serial passaging as previously described (9-11). For nelfinavir treatment studies, 6-week-old female NOD/SCID mice (Charles River Labs, Frederick, MD, USA) were injected subcutaneously in both rear flanks with $2 \times 10^{6}$ LX48 or LX44 PDX tumor cells in $50 \mu \mathrm{l}$ phosphate-buffered saline and $50 \mu \mathrm{BD}$ Matrigel Basement Membrane Matrix (BD Biosciences). When the transplanted tumors reached a volume of $50-100 \mathrm{~mm}^{3}$, mice were divided into the following two groups (10 mice per group): intraperitoneal injection of either vehicle (4\% DMSO, 5\% polyethylene glycol, 5\% Tween 80 in saline) once daily for 13 or 15 days, or $100 \mathrm{mg} / \mathrm{kg}$ nelfinavir once daily for 13 or 15 days. Animal weights and tumor size were measured every other day. In all studies, tumor volume was calculated using the formula $\mathrm{v}=\left(a b^{2}\right) / 2$, where $a$ was the long axis and $b$ was the short axis of the tumor. We conducted in vivo experiments using a protocol approved by the Animal Care and Use Committee of the Johns Hopkins University, Baltimore, Maryland (Protocol Number: MO12M148). The primary study endpoint was the efficacy of tumor growth inhibition, and a secondary endpoint was the evaluation of the biomarkers.

Statistical analysis. Statistical significance of differences observed in drug-treated and untreated cells was analyzed using one-way ANOVA, and multiple comparisons were then performed using the Bonferroni test. All analyses were performed using GraphPad Prism software version 9 (GraphPad Software, Inc., San Diego, CA, USA). Statistical significance was set at $p<0.05$.

\section{Results}

Nelfinavir inhibits proliferation of SCLC cells. To assess the effects on cellular proliferation, nelfinavir was tested at different concentrations in a series of four SCLC cell lines. Nelfinavir showed cytostatic effect at $10 \mu \mathrm{M}$ nelfinavir for $72 \mathrm{~h}$ (Figure 1A) and cytotoxicity at $20 \mu \mathrm{M}$ (Figure $1 \mathrm{~A}$ and B). The efficacy of nelfinavir against SCLC cells was confirmed by measuring total cell death (Figure 1C). Treatment with $10 \mu \mathrm{M}$ 
A

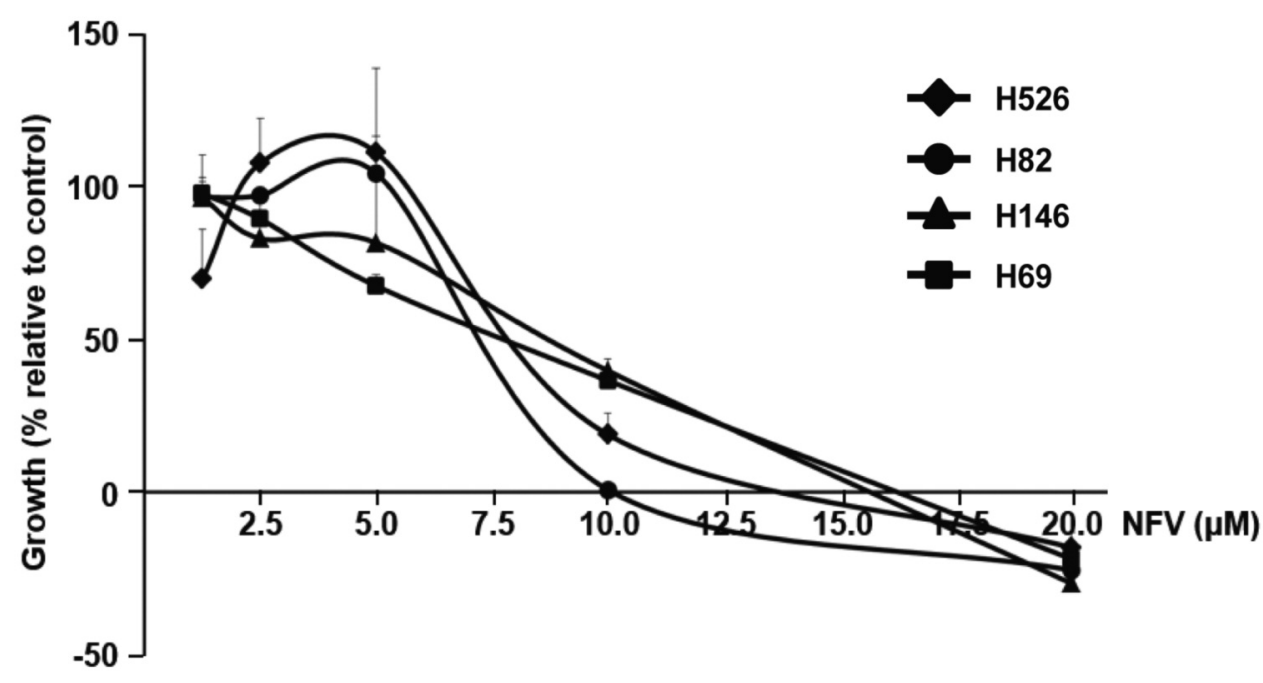

B
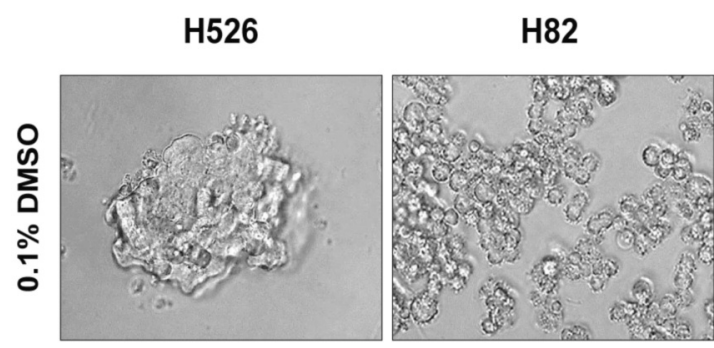

H146

H69
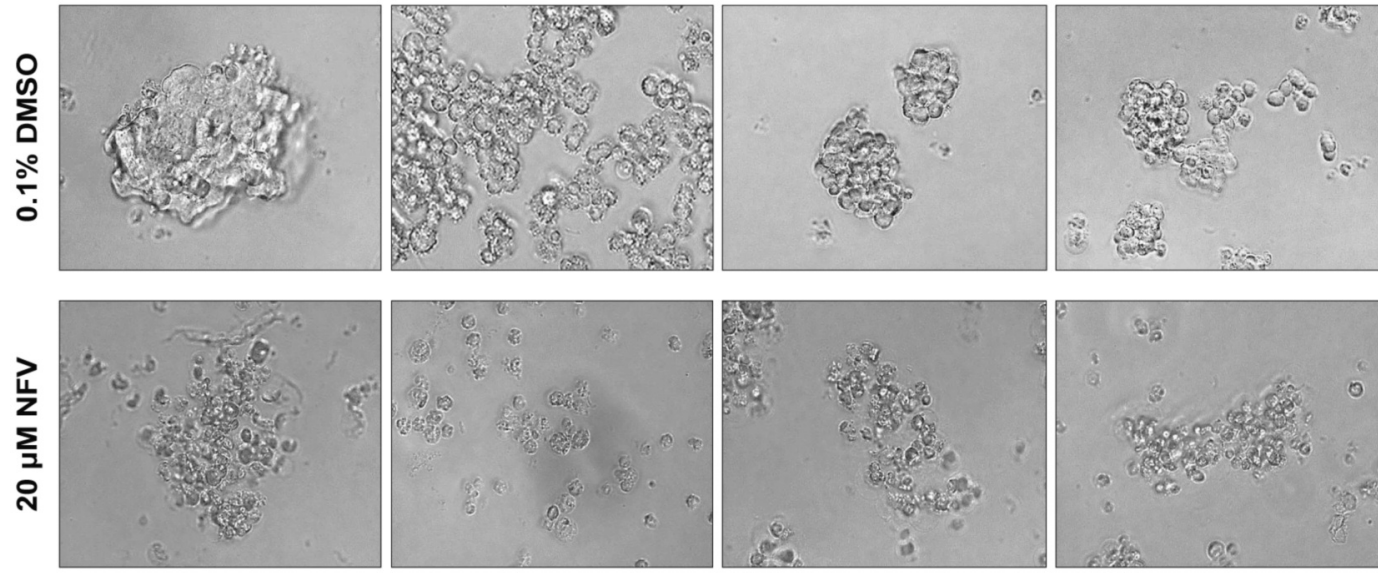

C

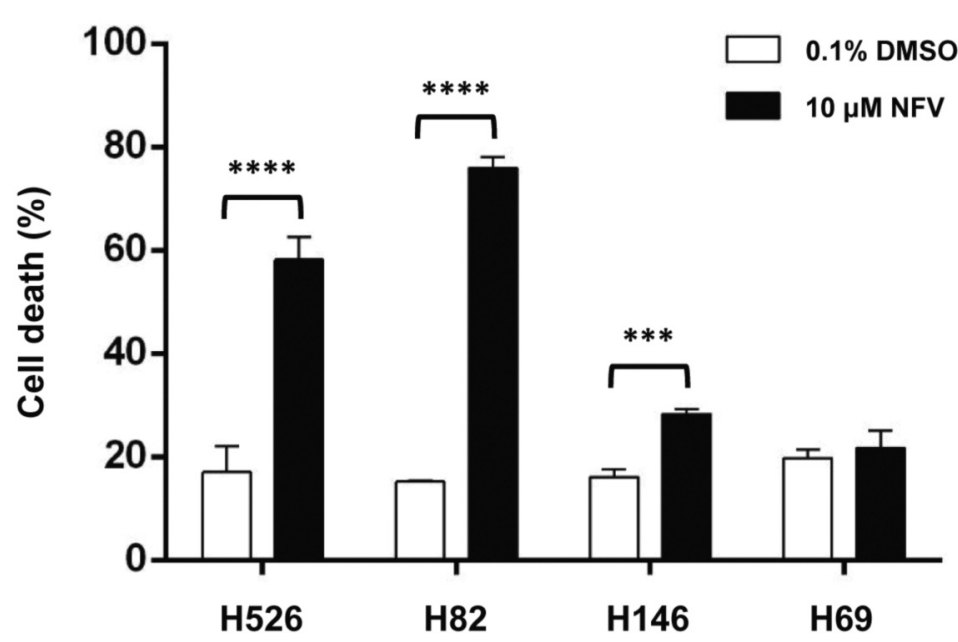

Figure 1. Nelfinavir (NFV) inhibits proliferation of small-cell lung cancer (SCLC) cells. A: Growth inhibition by NFV. SCLC cells were treated with NFV at the indicated concentrations for 72 h. B: SCLC cells were treated with either dimethyl sulfoxide (DMSO) or $20 \mu M$ NFV for 72 h. Optical microscopy images are shown (40x magnification). C: For total cell death assay, SCLC cells were treated with either $0.1 \%$ DMSO or $10 \mu M$ NFV for $72 \mathrm{~h}$, and then harvested and analyzed using cell death assays as described in the Materials and Methods. Data are the mean+SD of at least three separate experiments. Significantly different at: $* * * p<0.001$ and $* * * * p<0.0001$ compared with vehicle treatment. 
nelfinavir for $72 \mathrm{~h}$ inhibited cell viability in SCLC cells, except for H69 cells. To confirm the efficacy of nelfinavir against H69 cells, we assessed apoptosis by quantifying sub2N DNA by flow cytometry. Treatment with $20 \mu \mathrm{M}$ nelfinavir for $48 \mathrm{~h}$ increased the proportion of apoptotic H69 cells (data not shown). These data suggest that nelfinavir is highly effective against SCLC cells in vitro.

Nelfinavir induces unfolded protein response (UPR), inhibits activation of $M T O R$, and reduces the expression of SCLCrelated molecules. Because nelfinavir induced UPR and increased the expression of the endogenous mTOR inhibitor SESN2 in breast and ovarian cancer cells and cervical adenocarcinoma cells (12), we performed biomarker analysis of the SCLC cells treated with nelfinavir in a time- and dosedependent manner. As shown in Figure 2, nelfinavir increased expression of the markers of UPR, such as ATF4, ATF3 and CHOP, as well as the expression of SESN2, which was associated with mTOR inhibition in SCLC cell lines, except for H69, which has a PIK3CA activating mutation (13). Interestingly, AMPK $\alpha$ was activated within $4 \mathrm{~h}$, which was independent of the induction of SESN2. In terms of SCLC-related molecules, nelfinavir reduced the expression of n-MYC, c-MYC, and aurora B in SCLC cells in a dosedependent manner (Figure 2). Although n-MYC in H69 cells was slightly inhibited by treatment with $20 \mu \mathrm{M}$ nelfinavir for $12 \mathrm{~h}$, we confirmed that nelfinavir at the same dose reduced the expression of n-MYC within $4 \mathrm{~h}$ in the early phase (data not shown). ASCL1 was clearly inhibited in H526, H82 and H146 cells, as was SOX2 in H146 cells; however, there was less inhibition of both in H69 cells. Taken together, these findings indicate that nelfinavir has pleiotropic mechanisms of action for the inhibition of growth of SCLC cells.

Pharmacological manipulation was performed to evaluate inhibition of $m$ TOR and induction of UPR. To assess whether mTOR inhibition and UPR induction by nelfinavir are involved in the growth inhibition of SCLC cells, we treated these cells with either rapamycin or tunicamycin. Although $\mathrm{H} 82$ cells were resistant to rapamycin, the other cells showed growth inhibition by nelfinavir, which was associated with mTOR inhibition, but no alteration in UPR markers and SCLC-related molecules (Figure 3A). In contrast, tunicamycin showed cytotoxicity in H146 cells and a cytostatic effect in the other cell lines, which was associated with UPR induction, as indicated by the increased expression of ATF4, ATF3 or CHOP. Interestingly, tunicamycin inhibited mTOR in SCLC cell lines, except for H146 (Figure 3B). Collectively, these findings indicate that the efficacy of nelfinavir in H526 cells might be based on mTOR inhibition as well as UPR induction, whereas those of nelfinavir in H82 and H146 cells are due to UPR induction rather than mTOR inhibition. The pleiotropic mechanisms of action of nelfinavir against SCLC are cell line-dependent.
Nelfinavir inhibits the growth of SCLC PDX tumors. To confirm the efficacy of nelfinavir in vivo, NOD/SCID mice bearing established LX48 (Figure 4A) and LX44 (Figure 4B) PDX tumors were treated with either a vehicle or $100 \mathrm{mg} / \mathrm{kg}$ nelfinavir. The treatment was well-tolerated and reduced LX48 PDX tumor growth by nearly $60 \%(p<0.001$, Figure $4 \mathrm{~A}$, left), in association with increased expression of ATF3 and the inhibition of aurora B, ASCL1, and mTOR $(p<0.05$ and $p<0.01$, Figure 4A, right). In LX44 PDX tumors, nelfinavir was also effective, decreasing growth by nearly $80 \%$ ( $p<0.0001$, Figure 4B, left), which was associated with increased expression of ATF4 and the inhibition of n-MYC, $1-\mathrm{MYC}$, and aurora B ( $p<0.05$ and $p<0.01$, Figure 4B, right). Collectively, these findings show that nelfinavir is highly effective against SCLC in vivo as well as in vitro.

\section{Discussion}

We investigated the efficacy of nelfinavir repurposed as an anticancer drug in the treatment of SCLC and demonstrated that nelfinavir showed antiproliferative effects, with mTOR inhibition and UPR induction as the mechanisms of action in vitro (Figure 5). Furthermore, nelfinavir inhibited the growth of SCLC PDX tumors, which was associated with mTOR inhibition and UPR induction. Additionally, SCLCrelated molecules such as MYC, aurora B, ASCL1, and SOX2 were inhibited by nelfinavir both in vitro and in vivo (Figure 5). Aurora B is a serine/threonine kinase that is associated with microtubules during chromosome movement in mitosis, and the inhibition of aurora B kinase is involved in a synthetic lethal interaction for cells that overexpress MYC by inhibiting cytokinesis through failure of both the $\mathrm{G}_{1} / \mathrm{S}$ and $\mathrm{G}_{2} / \mathrm{M}$ checkpoints (14). Additionally, Sos et al. reported that knockdown of aurora B kinase resulted in a reduction of cell viability in $M Y C$-amplified SCLC cells (15). Although the mechanisms of action by which nelfinavir reduces the expression of $\mathrm{MYC}$, aurora $\mathrm{B}, \mathrm{ASCL} 1$, and SOX2 remain to be determined, nelfinavir is a potent multitargeted inhibitor for SCLC treatment.

We found that nelfinavir inhibited mTOR activation, as S6 phosphorylation decreased in SCLC cell lines, except for H69 (Figure 2). Brüning et al. reported that nelfinavir induced ATF4, which regulated the expression of SESN2, resulting in mTOR inhibition (12), which supports the results presented here. In contrast, we found that mTOR was inhibited within $4 \mathrm{~h}$ before inducing the expression of SESN2 by nelfinavir. SESN2-independent mTOR inhibition in the early phase might be caused by the activation of AMPK $\alpha$ during treatment with nelfinavir because AMPK $\alpha$ is a negative regulator of mTOR through the activation of tuberous sclerosis 2 (16). Nelfinavir causes mitochondrial depolarization in lung cancer cells (data not shown), which activates AMPK $\alpha$ (17). In H69 cells (Figure 2), nelfinavir 


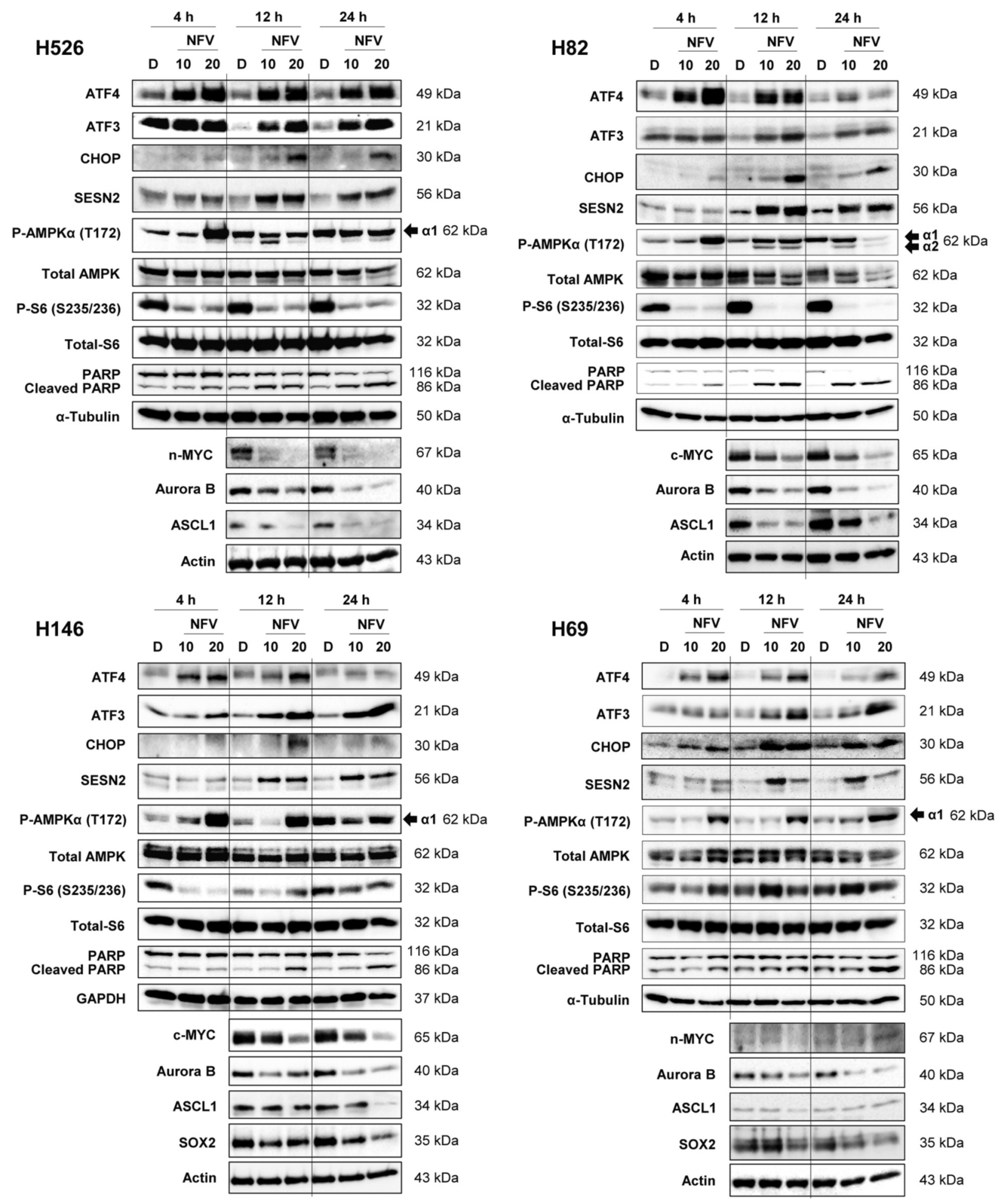

Figure 2. Nelfinavir (NFV) induces the unfolded protein response (UPR), inhibits mammalian/mechanistic target of rapamycin (mTOR) activation, and reduces the expression of small-cell lung cancer (SCLC)-related molecules. SCLC cell lines H526, H82, H146 and H69 were treated with 0.1\% dimethyl sulfoxide (D), $10 \mu \mathrm{M}$, or $20 \mu \mathrm{M}$ nelfinavir for 4, 12 and $24 \mathrm{~h}$. SCLC-related markers were assessed using immunoblotting analysis. ATF4: Activating transcription factor 4; ATF3: activating transcription factor 3; CHOP: CCAAT-enhancer-binding protein homologous protein; SESN2: sestrin-2; AMPK: 5' AMP-activated protein kinase; S6: S6 ribosomal protein; PARP: poly ADP-ribose polymerase; MYC: myelocytomatosis oncogene; ASCL1: achaete-scute homolog 1; GAPDH: glyceraldehyde-3-phosphate dehydrogenase; and SOX2: SRY-box transcription factor 2. 


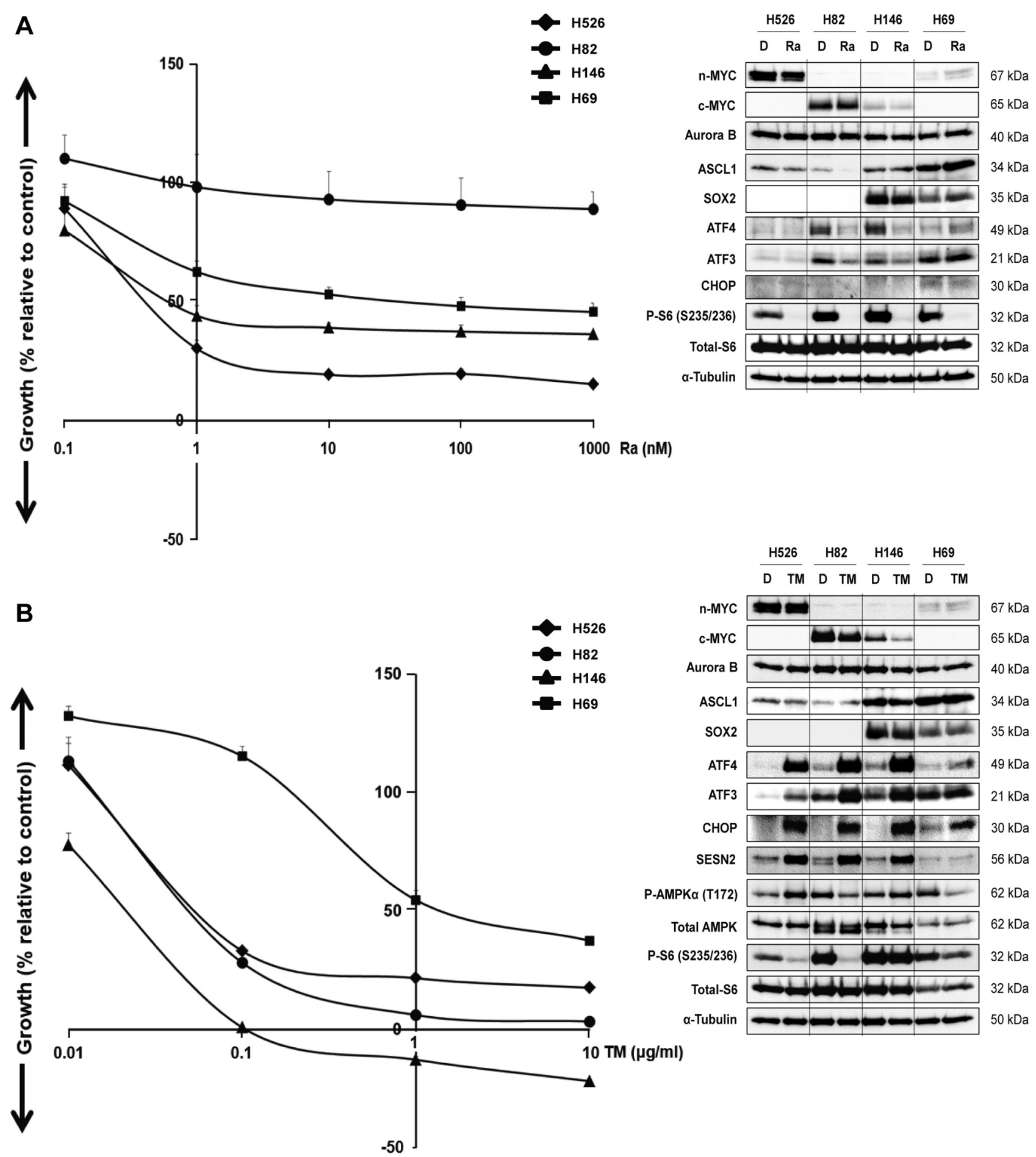

Figure 3. Pharmacological manipulation for inhibition of mammalian/mechanistic target of rapamycin (mTOR) and induction of the unfolded protein response in small-cell lung cancer (SCLC) cell lines H526, H82, H146 and H69. Inhibition of mTOR by rapamycin (Ra) (A) and induction of the unfolded protein response by tunicamycin $(T M)(B)$. Left panel: SCLC cells were treated with rapamycin or tunicamycin at the indicated concentrations for $72 \mathrm{~h}$. Growth inhibition was assessed using a cell proliferation assay as described in the Materials and Methods. Data are the mean $+S D$ of at least three separate experiments; note concentration axes are logarithmic. Right panel: SCLC cells were treated with 100 nM rapamycin or $1 \mu \mathrm{g} / \mathrm{ml}$ tunicamycin for $12 \mathrm{~h}$ and biomarker analyses were then performed using immunoblotting analysis. MYC: Myelocytomatosis oncogene; ASCL1: achaete-scute homolog 1; SOX2: SRY-box transcription factor 2; ATF4: activating transcription factor 4; ATF3: activating transcription factor 3; CHOP: CCAAT-enhancer-binding protein homologous protein; S6: S6 ribosomal protein. 
A

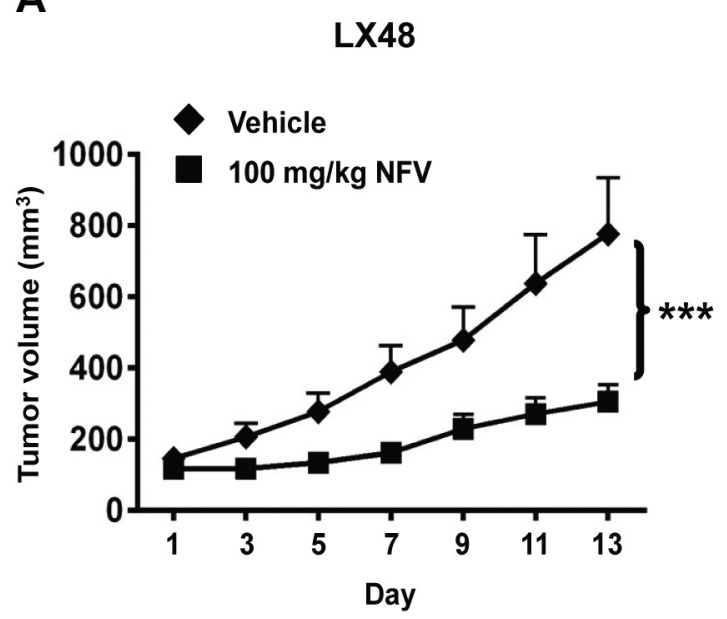

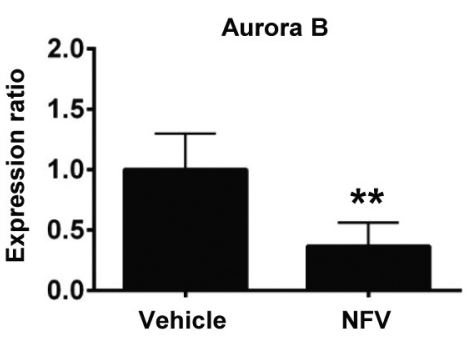
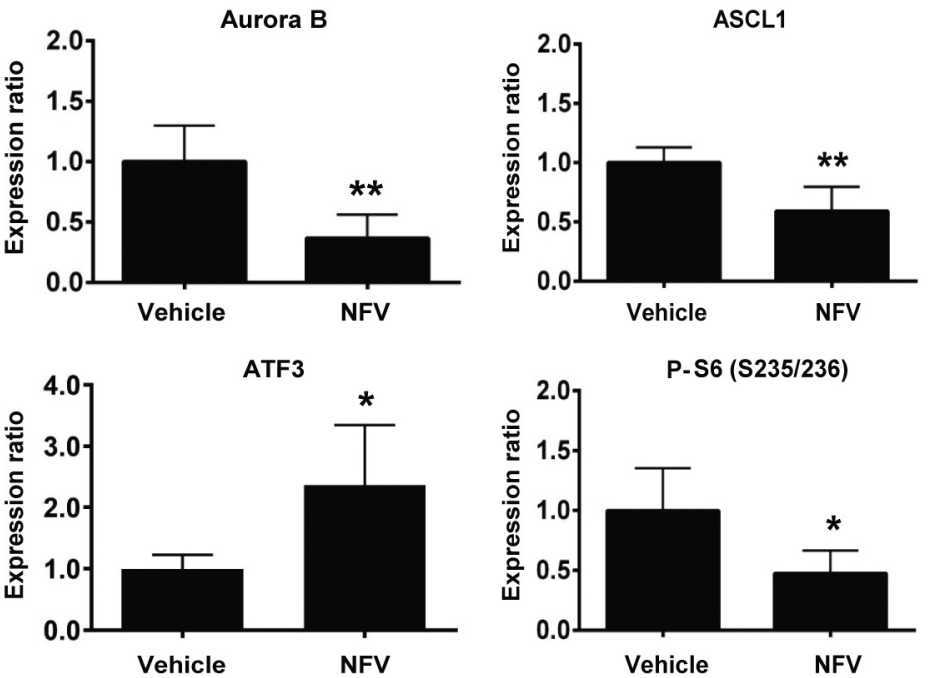

P.S6 (S235/236)

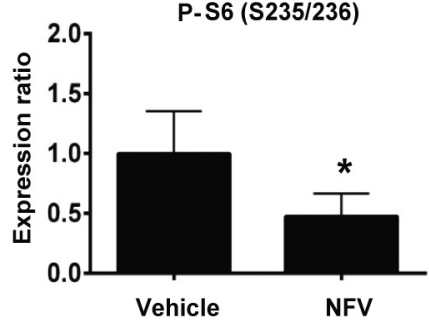

B
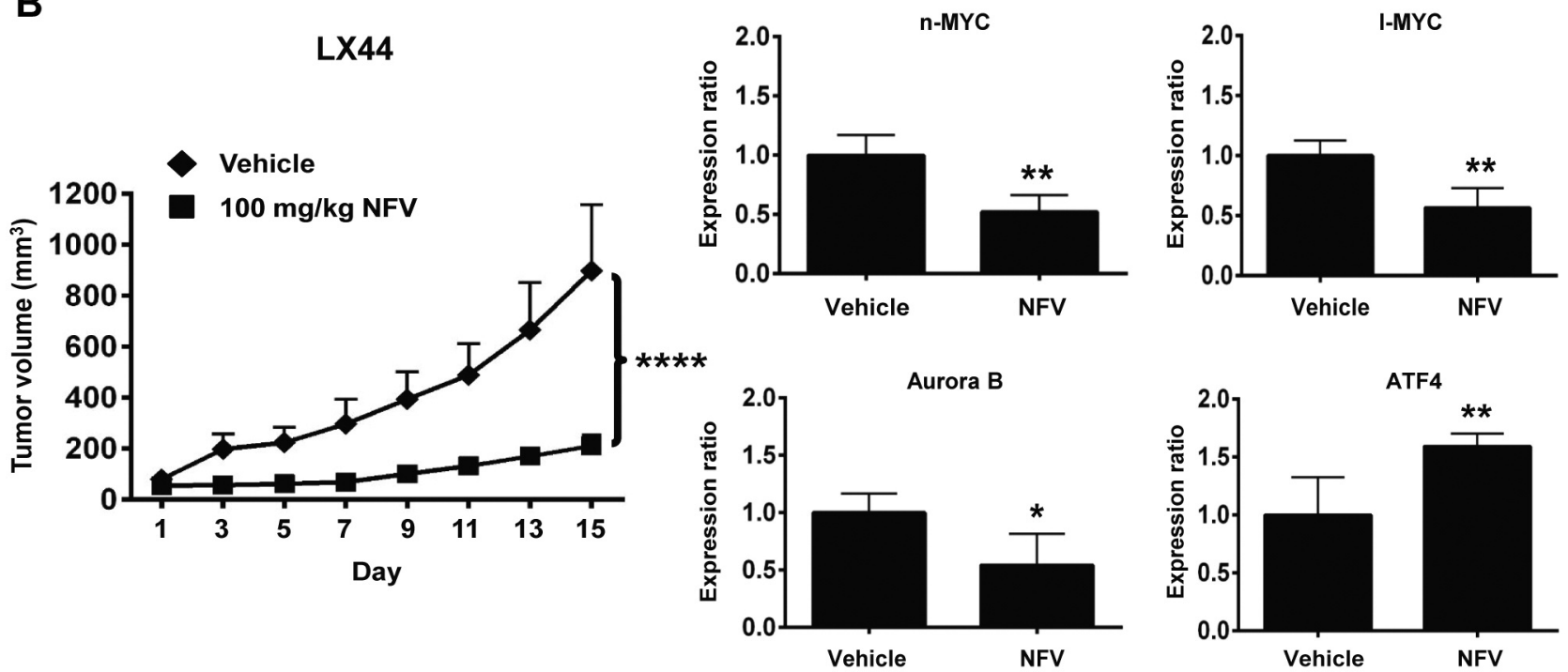

Figure 4. Nelfinavir (NFV) inhibits the growth of small-cell lung cancer (SCLC) patient-derived xenograft (PDX) tumors. LX48 (A) and LX44 (B) PDX tumors were grown in NOD/SCID mice. Biomarker analyses for SCLC treatment with nelfinavir were performed using immunoblotting analysis in each right panel. At the end of the study, LX48 and LX44 PDX tumors were excised for immunoblotting analysis of the following markers: Aurora $B$; achaete-scute homolog 1 (ASCL1); activating transcription factor 3 (ATF3); P-S6 ribosomal protein (P-S6); n-myelocytomatosis oncogene (n$M Y C)$ and activating transcription factor 3 (ATF4). Densitometry was performed using ImageJ version 1.52 software (25). The level of each marker was normalized to actin $(A)$ or $\alpha$-tubulin $(B)$ for each sample. Data are the mean+SD of tumors from 10 mice. Significantly different at: * $<0.05$, $* * p<0.01, * * * p<0.001$ and $* * * * p<0.0001$ compared with vehicle treatment.

activated AMPK $\alpha$ and increased the expression of ATF4 and SESN2; however, mTOR was not inhibited, which is explained by the fact that H69 cells have a PIK3CA activating mutation (13).

Neuroendocrine neoplasms of the lung are categorized as well-differentiated neuroendocrine tumors (NETs), otherwise termed carcinoid, and neuroendocrine carcinomas, including
SCLC and large-cell neuroendocrine carcinomas that are poorly differentiated. Everolimus, an oral mTOR inhibitor, has shown antitumor activity in adult patients with advanced gastrointestinal or lung NETs, resulting in Food and Drug Administration-approved treatment (18). In contrast, for SCLC, everolimus failed to show a significant effect on survival in patients with relapsed SCLCs (19). Lee et al. 


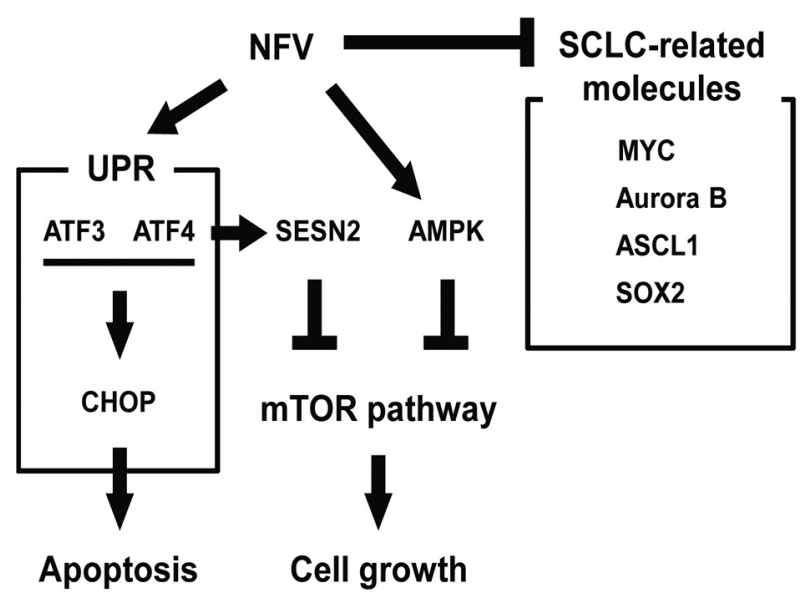

Figure 5. Nelfinavir (NFV) induces the unfolded protein response (UPR) and inhibits both the mammalian/mechanistic target of rapamycin (mTOR) pathway and expression of small-cell lung cancer (SCLC)related molecules. ATF3: Activating transcription factor 3; ATF4: activating transcription factor 4; CHOP: CCAAT-enhancer-binding protein homologous protein; SESN2: sestrin-2; AMPK: 5' AMPactivated protein kinase; MYC: myelocytomatosis oncogene; ASCL1: achaete-scute homolog 1; SOX2: SRY-box transcription factor 2.

reported mTOR activation in limited-stage SCLC to be significantly higher than in extended-stage SCLC, suggesting that i) mTOR activation might play a crucial role in the initiation of SCLC cells, and ii) inhibition of mTOR for limited-stage SCLC might be more effective than for extended-stage SCLC because of high p-mTOR expression (20). This supports our previous finding that mTOR activation is involved in NSCLC tumorigenesis $(21,22)$. Nelfinavir inhibits both mTOR activation and the expression of SCLCrelated molecules that play a role in tumorigenesis, suggesting its efficacy in preventing SCLC development or progression.

Recently, Kern et al. reported that mTOR is an essential kinase in a subset of SCLC PDX tumors, including our LX48 mouse model, using functional genomics with an shRNA kinome library. Additionally, mTOR inhibition was found to reduce the growth of PDX tumors and sensitize PDX to conventional chemotherapy, such as cisplatin and etoposide (23). Moreover, nelfinavir combined with other chemotherapies or radiation can be safe and can produce a promising response, based on a phase I/II trial of nelfinavir with concurrent chemoradiation in advanced NSCLC that has been reported (24). These findings support our data that mTOR inhibition by nelfinavir is an attractive target for SCLC therapy, and nelfinavir might sensitize both limitedstage SCLC to concurrent chemoradiation and extendedstage SCLC to conventional chemotherapy.

In conclusion, we demonstrated that nelfinavir is highly effective against SCLC in vitro and in vivo. Nelfinavir is well-tolerated in patients with cancer and showed its efficacy against NETs in a phase I trial (8). Collectively, these findings suggest a possible value of incorporating nelfinavir into clinical trials for patients with SCLC.

\section{Conflicts of Interest}

The Authors report no financial or other interests that could be construed as conflicts of interest.

\section{Authors' Contributions}

Conceived and designed the experiments: S.K. and P.A.D. Performed the experiments: S.K., N.C. and J.J.G. Analyzed the data: S.K., J.J.G. and C.L.H. Wrote the article: S.K. and P.A.D

\section{Acknowledgements}

The Authors would like to thank Elen Romero, Dawn SaberonBrown, and Sherrie Hawkes for veterinary services (Oncology Animal Resources, Sidney Kimmel Comprehensive Cancer Center). This work was supported by start-up funding from Johns Hopkins University School of Medicine to P.A.D. and JSPS KAKENHI Grant Number JP20K07646 to S. K.

\section{References}

1 Sabari JK, Lok BH, Laird JH, Poirier JT and Rudin CM: Unravelling the biology of SCLC: Implications for therapy. Nat Rev Clin Oncol 14: 549-561, 2017. PMID: 28534531. DOI: 10.1038/nrclinonc.2017.71

2 Bunn PA, Minna JD, Augustyn A, Gazdar AF, Ouadah Y, Krasnow MA, Berns A, Brambilla E, Rekhtman N, Massion PP, Niederst M, Peifer M, Yokota J, Govindan R, Poirier JT, Byers LA, Wynes MW, McFadden DG, MacPherson D, Hann CL, Farago AF, Dive C, Teicher BA, Peacock CD, Johnson JE, Cobb MH, Wendel HG, Spigel D, Sage J, Yang P, Pietanza MC, Krug LM, Heymach J, Ujhazy P, Zhou C, Goto K, Dowlati A, Christensen CL, Park K, Einhorn LH, Edelman MJ, Giaccone G, Gerber DE, Salgia R, Owonikoko T, Malik S, Karachaliou N, Gandara DR, Slotman BJ, Blackhall F, Goss G, Thomas R, Rudin CM and Hirsch FR: Small cell lung cancer: Can recent advances in biology and molecular biology be translated into improved outcomes? J Thorac Oncol 11: 453-474, 2016. PMID: 26829312. DOI: $10.1016 /$ j.jtho.2016.01.012

3 Augustyn A, Borromeo M, Wang T, Fujimoto J, Shao C, Dospoy PD, Lee V, Tan C, Sullivan JP, Larsen JE, Girard L, Behrens C, Wistuba II, Xie Y, Cobb MH, Gazdar AF, Johnson JE, Minna JD and Vogt PK: ASCL1 is a lineage oncogene providing therapeutic targets for high-grade neuroendocrine lung cancers. Proc Natl Acad Sci USA 111: 14788-14793, 2014. PMID: 25267614. DOI: 10.1073/pnas.1410419111

4 Gazdar AF, Bunn PA and Minna JD: Small-cell lung cancer: What we know, what we need to know and the path forward. Nat Rev Cancer 17: 725-737, 2017. PMID: 29077690. DOI: 10.1038/nrc.2017.87

5 Rudin CM, Durinck S, Stawiski EW, Poirier JT, Modrusan Z, Shames DS, Bergbower EA, Guan Y, Shin J, Guillory J, Rivers CS, Foo CK, Bhatt D, Stinson J, Gnad F, Haverty PM, Gentleman R, 
Chaudhuri S, Janakiraman V, Jaiswal BS, Parikh C, Yuan W, Zhang Z, Koeppen H, Wu TD, Stern HM, Yauch RL, Huffman KE, Paskulin DD, Illei PB, Varella-Garcia M, Gazdar AF, De Sauvage FJ, Bourgon R, Minna JD, Brock MV and Seshagiri S: Comprehensive genomic analysis identifies SOX2 as a frequently amplified gene in small-cell lung cancer. Nat Genet 44: 1111-1116, 2012. PMID: 22941189. DOI: 10.1038/ng.2405

6 Gills JJ, LoPiccolo J, Tsurutani J, Shoemaker RH, Best CJM, Abu-Asab MS, Borojerdi J, Warfel NA, Gardner ER, Danish M, Hollander MC, Kawabata S, Tsokos M, Figg WD, Steeg PS and Dennis PA: Nelfinavir, a lead HIV protease inhibitor, is a broadspectrum, anticancer agent that induces endoplasmic reticulum stress, autophagy, and apoptosis in vitro and in vivo. Clin Cancer Res 13: 5183-5194, 2007. PMID: 17785575. DOI: 10.1158/ 1078-0432.CCR-07-0161

7 Kawabata S, Gills JJ, Mercado-Matos JR, LoPiccolo J, Wilson W, Hollander MC and Dennis PA: Synergistic effects of nelfinavir and bortezomib on proteotoxic death of NSCLC and multiple myeloma cells. Cell Death Dis 3: e353-12, 2012. PMID: 22825471. DOI: 10.1038/cddis.2012.87

8 Blumenthal GM, Gills JJ, Ballas MS, Bernstein WB, Komiya T, Dechowdhury R, Morrow B, Root H, Chun G, Helsabeck C, Steinberg SM, LoPiccolo J, Kawabata S, Gardner ER, Figg WD and Dennis PA: A phase I trial of the HIV protease inhibitor nelfinavir in adults with solid tumors. Oncotarget 5: 8161-8172, 2014. PMID: 25327558. DOI: 10.18632 /oncotarget. 2415

9 Hann CL, Daniel VC, Sugar EA, Dobromilskaya I, Murphy SC, Cope L, Lin X, Hierman JS, Wilburn DL, Watkins DN and Rudin CM: Therapeutic efficacy of ABT-737, a selective inhibitor of BCL-2, in small cell lung cancer. Cancer Res 68: 2321-2328, 2008. PMID: 18381439. DOI: 10.1158/00085472.CAN-07-5031

10 Poirier JT, Dobromilskaya I, Moriarty WF, Peacock CD, Hann CL and Rudin CM: Selective tropism of Seneca Valley virus for variant subtype small cell lung cancer. J Natl Cancer Inst 105: 1059-1065, 2013. PMID: 23739064. DOI: 10.1093/jnci/djt130

11 Gardner EE, Connis N, Poirier JT, Cope L, Dobromilskaya I, Gallia GL, Rudin CM and Hann CL: Rapamycin rescues ABT737 efficacy in small cell lung cancer. Cancer Res 74: 2846-2856, 2014. PMID: 24614082. DOI: 10.1158/0008-5472.CAN-13-3460

12 Brüning A, Rahmeh M and Friese K: Nelfinavir and bortezomib inhibit mTOR activity via ATF4-mediated sestrin-2 regulation. Mol Oncol 7: 1012-1018, 2013. PMID: 23916134. DOI: 10.1016/j.molonc.2013.07.010

13 Walls M, Baxi SM, Mehta PP, Liu KKC, Zhu J, Estrella H, Li $\mathrm{C}$, Zientek M, Zong Q, Smeal T and Yin MJ: Targeting small cell lung cancer harboring PIK3CA mutation with a selective oral PI3K inhibitor PF-4989216. Clin Cancer Res 20: 631-643, 2014. PMID: 24240111. DOI: 10.1158/1078-0432.CCR-13-1663

14 Yang D, Liu H, Goga A, Kim S, Yuneva M and Bishop JM: Therapeutic potential of a synthetic lethal interaction between the MYC proto-oncogene and inhibition of aurora-B kinase. Proc Natl Acad Sci USA 107: 13836-13841, 2010. PMID: 20643922. DOI: $10.1073 /$ pnas.1008366107

15 Sos ML, Dietlein F, Peifer M, Schötle J, Balke-Want H, Mutler C, Koker M, Richters A, Heynck S, Malchers F, Heuckmann JM, Seidel D, Eyers PA, Ullrich RT, Antonchick AP, Vintonyak VV, Schneider PM, Ninomiya T, Waldmann H, Buttner R, Rauh D, Heukamp LC and Thomas RK: A framework for identification of actionable cancer genome dependencies in small cell lung cancer. Proc Natl Acad Sci USA 109: 17034-17039, 2012. PMID: 23035247. DOI: 10.1073/pnas.1207310109

16 Memmott RM and Dennis PA: Akt-dependent and -independent mechanisms of mTOR regulation in cancer. Cell Signal 21: 656664, 2009. PMID: 19166931. DOI: 10.1016/j.cellsig.2009.01.004

17 Barbour JA and Turner N: Mitochondrial stress signaling promotes cellular adaptations. Int J Cell Biol 2014: 156020, 2014. PMID: 24587804. DOI: $10.1155 / 2014 / 156020$

18 Yao JC, Fazio N, Singh S, Buzzoni R, Carnaghi C, Wolin E, Tomasek J, Raderer M, Lahner H, Voi M, Pacaud LB, Rouyrre N, Sachs C, Valle JW, Fave GD, Van Cutsem E, Tesselaar M, Shimada Y, Oh DY, Strosberg J, Kulke MH and Pavel ME: Everolimus for the treatment of advanced, non-functional neuroendocrine tumours of the lung or gastrointestinal tract (RADIANT-4): A randomised, placebo-controlled, phase 3 study. Lancet 387: 968-977, 2016. PMID: 26703889. DOI: 10.1016/S0140-6736(15)00817-X

19 Tarhini A, Kotsakis A, Gooding W, Shuai Y, Petro D, Friedland D, Belani CP, Dacic S and Argiris A: Phase II study of everolimus (RAD001) in previously treated small cell lung cancer. Clin Cancer Res 16: 5900-5907, 2010. PMID: 21045083. DOI: 10.1158/1078-0432.CCR-10-0802

20 Lee JH, Kang KW and Lee HW: Expression of phosphorylated mTOR and its clinical significances in small cell lung cancer. Int J Clin Exp Pathol 8: 2987-2993, 2015. PMID: 26045808.

21 Granville CA, Warfel N, Tsurutani J, Hollander MC, Robertson M, Fox SD, Veenstra TD, Issaq HJ, Linnoila RI and Dennis PA: Identification of a highly effective rapamycin schedule that markedly reduces the size, multiplicity, and phenotypic progression of tobacco carcinogen-induced murine lung tumors. Clin Cancer Res 13: 2281-2289, 2007. PMID: 17404113. DOI: 10.1158/1078-0432.CCR-06-2570

22 Kawabata S, Mercado-Matos JR, Hollander MC, Donahue D, Wilson W, Regales L, Butaney M, Pao W, Wong KK, Jänne PA and Dennis PA: Rapamycin prevents the development and progression of mutant epidermal growth factor receptor lung tumors with the acquired resistance mutation T790M. Cell Rep 7: 1824-1832, 2014. PMID: 24931608. DOI: 10.1016/j.celrep.2014.05.039

23 Kern JA, Kim J, Foster DG, Mishra R, Gardner EE, Poirier JT, Rivard C, Yu H, Finigan JH, Dowlati A, Rudin CM and Tan AC: Role of mTOR as an essential kinase in SCLC. J Thorac Oncol 15: 1522-1534, 2020. PMID: 32599072. DOI: 10.1016/j.jtho. 2020.05.026

24 Rengan R, Mick R, Pryma DA, Lin LL, Christodouleas J, Plastaras JP, Simone CB, Gupta AK, Evans TL, Stevenson JP, Langer CJ, Kucharczuk J, Friedberg J, Lam S, Patsch D, Hahn SM and Maity A: Clinical outcomes of the HIV protease inhibitor nelfinavir with concurrent chemoradiotherapy for unresectable stage IIIA/IIIB non-small cell lung cancer: A phase 1/2 trial. JAMA Oncol 5: 1464-1472, 2019. PMID: 31436839. DOI: 10.1001/jamaoncol.2019.2095

25 Schneider CA, Rasband WS and Eliceiri KW: NIH Image to ImageJ: 25 Years of image analysis. Nat Methods 9: 671-675, 2012. PMID: 22930834. DOI: 10.1038/nmeth.2089

Received October 30, 2020

Revised November 18, 2020

Accepted November 23, 2020 